\title{
IDENTIFICATION AND SYSTEMATIZATION OF POLITENESS STRATEGIES IN FRENCH-LANGUAGE INTERNET DISCOURSE IN THE ASPECT OF POLITICAL CORRECTNESS AND TOLERANCE
}

\author{
Ekatherina D. Kalinnikova ${ }^{1}$, Vladislav E. Anisimov ${ }^{2}$ \\ ${ }^{1} \mathrm{PhD}$ student, Department of Foreign Languages, Philological Faculty, RUDN University, \\ Russia, kate.dk01@gmail.com \\ ${ }^{2} \mathrm{PhD}$, Department of Foreign Languages, Philological Faculty, RUDN University, Russia, \\ anisimov.vladislav.95@mail.ru
}

\begin{abstract}
The article examines the language means of expressing politeness in the aspect of political correctness and tolerance in the French-speaking segment of the modern Internet space. The aim of this paper is to identify and systematize the politeness strategies implemented in the modern French-language Internet discourse in the aspect of political correctness and tolerance towards certain social groups. The methods of observation, description, interpretation, sampling and quantitative data collection techniques were applied. The research is based on a corpus of small-format texts in online French-language environment (social networks) between the years 2017-2021. The total number of posts and comments is 1,518. The results of the study were the presentation of modern trends, reflecting the phenomena of tolerance and political correctness, at the linguistic and cognitive levels. The research materials can be used in teaching graduate students of universities in the framework of the study of modern culture, the culture of the modern French language, as well as in thematic language classes for the development of new lexical, linguocultural and grammatical material.
\end{abstract}

Keywords: politeness, tolerance, correctness, French-language discourse, Internet discourse.

\section{INTRODUCTION}

Nowadays, tolerance is the latest global trend, reflecting the attitude of the host society towards individual social groups organized according to the principle of inclusion: sexual minorities, ethnic groups, migrants, representatives of various subcultures, etc. The trend of tolerance reflects the modern desire of society to globalize and create a global community. The main feature of tolerance is the acceptance of the otherness of different members of society and their integration into general social interactions. Tolerance implies a respectful attitude towards manifestations of otherness of different society members, a polite attitude towards their culture, values, etc. The opposite trend is intolerance, which reflects a negative reaction to the inclusion of distinctive elements in the established framework of social norms (Asmus, Masgutova, Zabolotneva 2020).

Political correctness is a socio-political ideological ersatz that exists in the language: unlike tolerance, which is an ideological and philosophical phenomenon, political correctness functions in speech (oral and written), and represents the decoding of the language by symbolic images of anti-racism, anti-sexism, ecology, etc. (Asmus 2018).

\section{TOLERANCE AND POLITICAL CORRECTNESS IN INTERNET DISCOURSE}

Tolerance and political correctness can be expressed through various types of behavior (speech behavior, actions) and manifest in the form of specific strategies that determine them. Thus, strategies of verbal behavior can be adequately implemented using various methods of implementing politeness and impoliteness in the format of a communicative act (oral or written) (Asmus 2019). 
Due to the specifics of information, the global Internet is becoming one of the most popular platforms for communication. Network communication can be carried out on special platforms - social networks, with the help of which users can leave messages to a specific addressee or in the format of a general message (visible to all network users). Due to the active growth in the number of users, the absence of time and geographical barriers, social networks are gaining more and more popularity as platforms for mass communication. Communication in social networks has its own characteristic features, including: convergence of constitutive signs of oral and written speech, high emotive saturation (using emotionally rich vocabulary, special index signs - e.g. emoji, etc.), graphic design of texts, spontaneity of generation texts, general availability, appeal to an indefinite addressee, publicity, reduction of officialdom, free stylistic design, etc. (Kalinnikova, Anisimov 2020).

\section{IMPLEMENTATION OF POLITNESS STRATEGIES IN MODERN FRENCH-LANGUAGE INTERNET DISCOURSE}

The phenomenon of tolerance and political correctness in the network discourse plays an important role, primarily due to the general availability of published messages and materials. The respect for the principles of mutual courtesy and the norms of netiquette in the framework of communication is a prerequisite for adequate interaction in the community of social networks. Linguistic politeness in the format of network communication can be expressed using various techniques designed to express the emotional, evaluative and subjective components of these phenomena (Shkineva, Kalinnikova, Borisova 2020). So, among such techniques may appear lexical means of expressing politeness, syntactic, grammatical, stylistic and graphic. The lexical means of expressing politeness include the use of special, neutral or positive words to designate groups to which tolerance is manifested. Also, the non-use of offensive, negative connotations or rude words and expressions belongs to lexical techniques as well. The stylistic means of expressing politeness in the aspect of tolerance can be the following: stylistic coloring of the text, sarcasm, irony and the use of special words (diminutives, official, slang etc.). Finally, the inversion, exclamative sentence and scaling particles (e.g. hashtags) are relating to the syntactic mean of politeness expression.

Let's consider examples that represent the use of various strategies of politeness in the aspect of political correctness and tolerance.

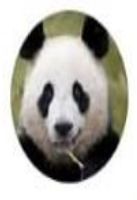

Gros Panda @GrosPan.... 16 окт. 20

Deux poids, deux mesures.

Les dissonances cognitives de la \#gauche.

- Je me demande toujours d'où vient cette inégalité de \#LLibertedexpression et quand le \#pluralisme d'idées va pouvoir revenir en \#france $\mathbf{I}$

\#communisme \#menaretrash \#feminisme \#pasdamalgame \#oppression 


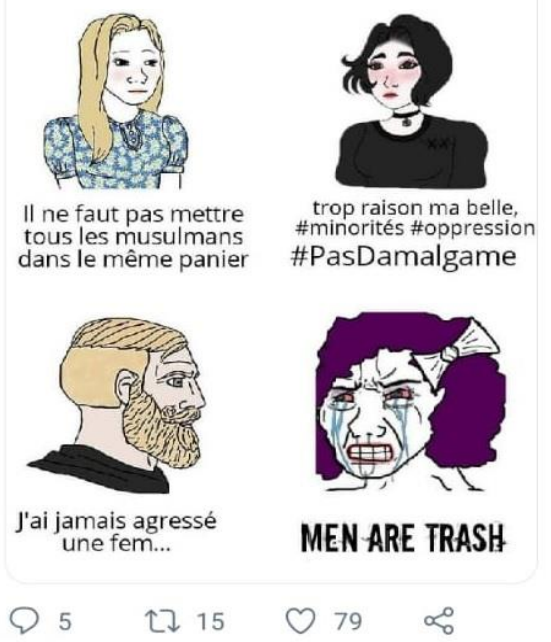

Example 1. Politeness strategies in the context of gender tolerance

According to the example case, the textual component of the message is underlined by a text-iconic image in the popular format of the so-called. "Meme" - an Internet meme - "a complex phenomenon of Internet communication, which is an integral, complete unit, with text and a picture in a square frame" (Kanashina 2017). Politeness strategies, in this case, are implemented through an indefinite personal appeal, implemented by the author of the message "Deux poids, deux mesures" (eng. "Double standards"), a semantic indication of logical dominants - by the means of an iconic image, the use of hashtags, dividing the text into three points (designation of the problem, question, own opinion), and the location of the author's own opinion with the help of introductory constructions at the end of the message. At the same time, the iconic component - the Internet meme - uses the strategy of sarcasm, while the text component implements the formal style of communication.

Another example case (example 2) demonstrates the formal use of politeness strategies in the context of network communication:

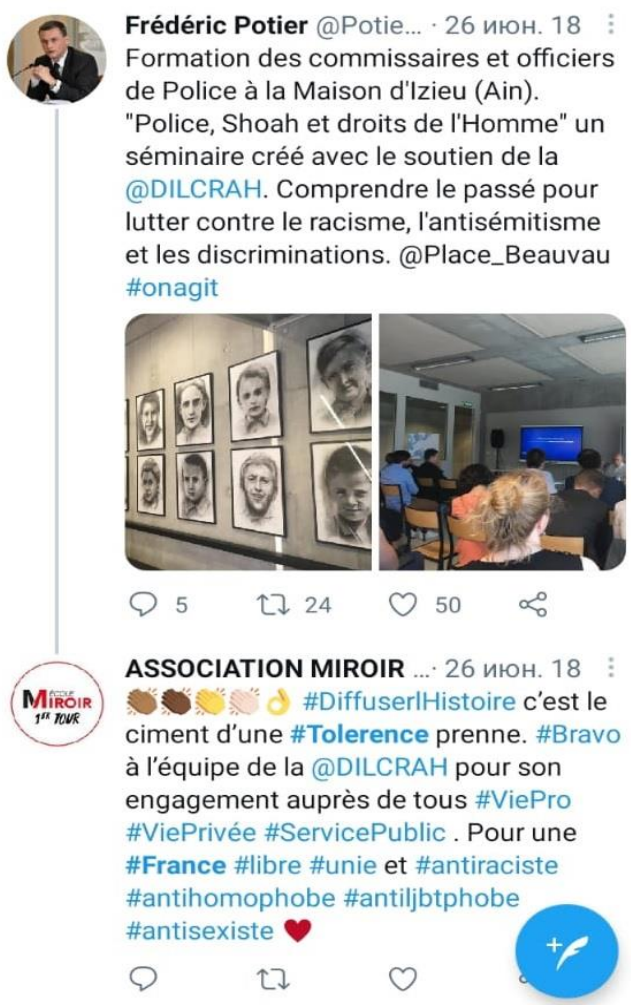

Example 2. Implementation of politeness strategies in the context of ethnic and religious tolerance 
In this post, to indicate the tendencies of tolerance and political correctness, a formal style of speech is used, as well as different indications of specific events, and facts within which this policy is implemented. Here the author uses different strategies of politeness as a formal style of communication with the corresponding grammatical constructions "un seminair créé avec le soutien de ..." ("a seminair created with support of ..."), "comprendre le passe pour lutter contre racisme ..." ("to understand the past to fight racism ... "). At the same time, we can observe the using of a reference to an unidentified person - a mass audience and hypertext labels - hashtags and appeals to designate persons and organizations related to the action and highlight keywords. At the same time, the iconic component contains two types of images as well: aesthetic, placed to attract the attention of a mass audience, and "field", shot in the format of a photo reportage, designed to emphasize the reality of the event taking place.

The opposite strategy is implemented by the commentary on the post in question, which also represents the popular politeness strategy in terms of tolerance and political correctness. First of all, attention can be paid to the use of iconic emoji symbols, which depict the same iconic sign (bravo), but using different colors, which should demonstrate political correctness in relation to ethnic and racial contexts. The second aspect is the use of special hashtag tags to indicate author's position instead of the coherent text. At the same time, the author of the comment combines in his message an appeal to the organizer of the action (@DILCRAH Délégation Interministérielle à la Lutte Contre le Racisme, l'Antisémitisme et la Haine anti-LGBT [Interministerial Delegation Against Racism, Anti-Semitism and Anti-LGBT Hate]), an appeal to national values (\#France, \#libre, \#unie [\#France, \#free, \#united]) and an appeal to various forms of tolerant social behavior (\#antiraciste, \#antiljbtfobe ect.)

\section{CONCLUSIONS}

The phenomenon of tolerance and political correctness is one of the most discussed issues in the modern French-language Internet discourse of social networks. The attitude towards these phenomena is demonstrated by social networks users by means of various strategies of politeness - from a formal style of communication to the use of special politically correct and tolerant emoji symbols. We can note that not all users adhere to positions of tolerance, however, they employ politeness strategies in relation to certain social groups (ethnic, gender, sexual, etc.).

Our research shows that the implementation of politeness occurs mainly using two main communication strategies: the formal politeness implementation, while authors utilize special formal speech patterns (generalized address, standard speech cliches, etc.), direct links to participants, events and indicators, as well as the iconic photo and video sequences in the format of evidence and/or confirmation. This type politeness strategies implementation is typical for officials and companies representatives in social networks, public figures and organizations.

The second type can be characterized as expressive: the implementation of politeness strategies in the context of tolerance and political correctness occurs through the use of special iconic components - emoji symbols, the active use of hashtag tags as keywords and their supernumber in relation to the text component, as well as the use of Internet memes, copyright images, etc. as an iconic component. Methods of indirect expression are used to represent one's own opinion on tolerance and political correctness: the use of irony, sarcasm, a rhetorical question, etc.

This work may be relevant for senior students of specialized language and political universities. The results of this work can be used as a visual material for courses on cultural linguistics, modern language stylistics, linguoculture of the countries of the target language (French).

The article was published with support from the Program of Strategic Academic Excellence, RUDN University.

\section{REFERENCE LIST}

Asmus NG, Masgutova MF, Zabolotneva OL (2020) Linguistic Features Of Gender Differences In Blog Communication // The European Proceedings of Social \& Behavioral Sciences, London: Future Academy. Pp. 45-52.

Asmus, NG (2019) Linguosemiotic Features Of Twitter Microblogging // The European Proceedings of Social \& Behavioral Sciences (EpSBS) conference proceedings. Pp. 653-660. 
Asmus, NG (2018) Linguistic peculiarities of the mobile phones and gadgets advertising discourse // The European Proceedings of Social \& Behavioral Sciences (EpSBS) conference proceedings. Pp. 664670.

Kanashina, SV (2017) What is an internet meme? // Scientific Bulletin of Belgorod State University. Series: Humanities. No. 28 (277). S. 84-90.

Kalinnikova, ED, Anisimov, VE (2020) Ethnocultural features of the french advertising discourse (based on french social advertising) // ADVED 2020- 6th International Conference on Advances in Education. Pp.263-268

Shkineva MA, Kalinnikova ED, Borisova AS (2020) Phenomenon of female solidarity in modern web-space // Actual problems of linguistics and linguodidactics of a foreign language of business and professional communication. Collection of materials of the IX International Scientific Conference. In 2 parts. P. 32. 